\title{
Post-Finasteride Syndrome - When will we Get the Courage to Fight the Dictating Pharma Industry - Despite Awareness of "Sexual, Neurological and Metabolic Side Effects in Young Men for Over a Decade"

\author{
Dr. Kulvinder Kochar Kaur, MD¹, Dr. Gautam Allahbadia, MD (Obstt \& Gynae), D.N.B², \\ Dr. Mandeep Singh, MD, DM.(Std) (Neurology) ${ }^{3}$ \\ ${ }^{1}$ Scientific Director, Dr Kulvinder Kaur Centre For Human Reproduction, Punjab, India. \\ ${ }^{2}$ Scientific Director, Ex-Rotunda-A Centre for Human Reproduction, Mumbai, India. \\ ${ }^{3}$ Consultant Neurologist, Swami Satyanand Hospital, Punjab, India.
} \\ *Corresponding Author: Dr. Kulvinder Kochar Kaur, MD, Scientific Director, Dr Kulvinder Kaur Centre For Human Reproduction, Punjab, India.
}

\begin{abstract}
Finasteride is a 5 alpha reductase inhibitor(5- $\alpha$ RI) that has been used for the treatment of benign prostatic hyperplasia (BPH) as well as androgenic alopecia for relatively young men for long. That a group of side effects not only develop following its use but persist following cessation of the drug with the syndrome coined as "Post Finasteride Syndrome "(PFS) has been realized for long. What is the reason that we as physicians refuse to appreciate this despite serious adverse effects like persistent sexual dysfunctions, suicidal ideation, and other metabolic effects like risk of developing type 2 diabetes mellitus (DM), lacrimal dysfunction, renal abnormalities we refuse to appreciate these drug induced syndrome. Infact when rimonabant (a CB1 receptor agonist)was being studied as an antiobesity syndrome and was shown to cause suicidal ideation immediately it was with drawn from trials. What pushes us not to use the same criteria for these 5- $\alpha$ RI including Finasteride and dutasteride knowing that how important they are in human physiology and how severe harm we might cause to then poor unknowing man who is not even told that he might develop erectile dysfunction, loss of pleasure in life a prize he has to pay to get his hair back. This comprehensive review has been done with an effort for our medical community who took hippocratic oath to serve the humanity why they cannot get up and protest against the side effects that in a subgroup of men might get irreversible side effects rather than label the poor men as psychotic or delusional. These symptoms have been emphasized by Traish along with other groups as men who have epigenetic susceptibility. Time has come that not only we start actually looking deep down into the pathophysiology and get an insight into this mysterious, elusive diagnosis that refuses to get accepted despite a lot of body of evidence.Hopefully a change in the attitude of our community will come.
\end{abstract}

Keywords: 5- $\alpha$ RI; "Post Finasteride Syndrome "(PFS); persistent sexual dysfunctions; suicidal ideation; BPH; metabolic dysfunctions

\section{INTRODUCTION}

5 -alpha reductases (5- $\alpha$-R's ) are a family of isozymes that get expressed in multiple host organs as well as tissues which has central nervous system(CNS) as a part. 5- $\alpha-R^{\prime}$ s have a crucial role in controlling as well as generation of male sexual differentiation as well as metabolism [1-6]. 5- $\alpha$-R's catalyzes the conversion of multiple gonadal, adrenal as well as CNS steroid precursors into active functional hormones as well as neuroactive steroids[9-11][(figure1). 
Post-Finasteride Syndrome - When will we Get the Courage to Fight the Dictating Pharma Industry - Despite Awareness of "Sexual, Neurological and Metabolic Side Effects in Young Men for Over a Decade"

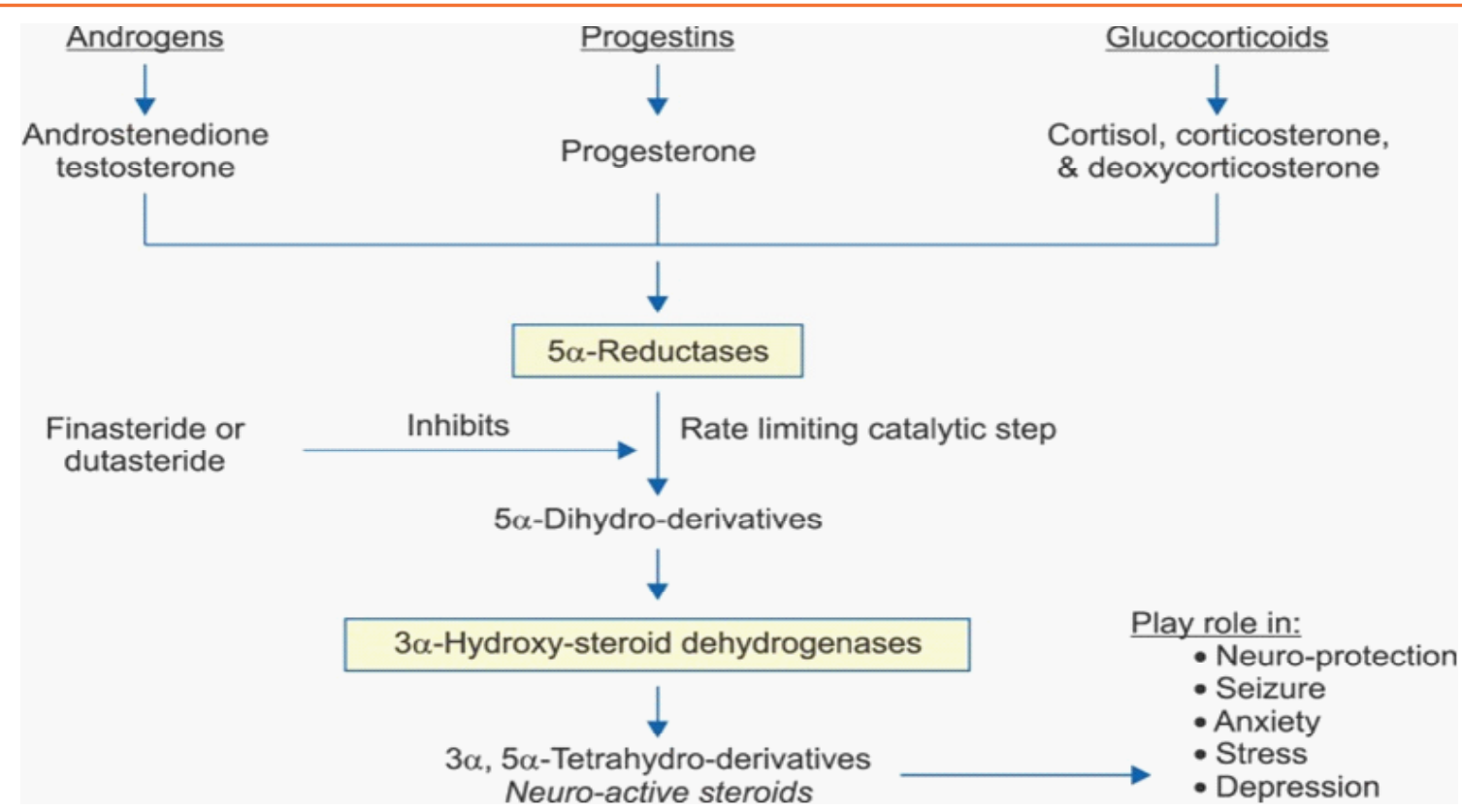

Fig 1. Courtesy ref number 7 -Transformation of androgens, progestins and glucocorticoids into $5 \alpha$ - dihydroderivatives by $5 \alpha$-reductases and tetrahydro-metabolites (neurosteroids) by $3 \alpha$ hydroxysteroid dehydrogenases. The rate limiting step in this pathway is the catalysis by $5 \alpha$-reductases.

Finasteride as well as dutasteride represent some of the 5- $\alpha$-R's-inhibitors (5- $\alpha$-RIs) that bind to active areas in $5-\alpha-R^{\prime}$ 's with great affinity. Their pharmacokinetics are in such a way that both of them prove to be literally irreversible inhibitors of 5- $\alpha$-R's having slow rate of dissociation, ending in a prolonged effect of the drug, irrespective of the dose given. The irreversible type of inhibition caused by these drugs might end in epigenetic alterations, like DNA methylation of the androgen receptorgene or the 5- $\alpha$ R's genes. Further, these drugs may work as endocrine disruptors, adding to various potential mechanism, leading to various potential mechanisms by which these drugs bring about bad, adverse sexual as well as psychological side effects. As 5- $\alpha$-dihydrotestosterone (5- $\alpha$ DHT) has a central part in erectile physiology [12-15], that includes activation of nitric oxide synthase (NOS) as well as enhancing the blood flow in penile tissues, inhibiting $5-\alpha-\mathrm{R}$ 's by finasteride or dutasteride leads toerectile dysfunction (ED). Animal model studies [12-15] showed reduced biosynthesis as well as circulation of 5- $\alpha$ DHT, decreased expression as well as activation of endothelial (eNOS) as well as neural (nNOS) nitric oxide synthases [12-15], hence ameliorating penile tissue relaxation and ending in ED. Further, lack of or decreased 5- $\alpha$ DHT causes penile trabecular smooth muscle cells death along with escalated deposition of connective tissue causing changes in penile tissue histoarchitecture along with impedance of its compliance and hence aiding in ED [13-15]. The sequelae of these pathophysiologic alterations is fibrosis (scarring) of penile tissue causing poor compliance of tissues, leakage via veins and finally ED [13-15].

Lot of preclinical studies stressed on the significance of neurosteroids in sustaining the CNS function [16-32]. As synthesis of neurosteroids is controlled by $5-\alpha-R^{\prime}$ s actions, inhibiting these enzymesin CNS viafinasteride or dutasteride decreases the bioavailability of these key physiological modulating agents. Actually lot of studies have studied the amounts of neurosteroids that are active in cerebrospinal fluid (CSF) of patients who had used Finasteride earlierand demonstrated continuing symptoms. A marked decrease in5- $\alpha$ DHT along with enhancement of testosterone (T) as well as $3-\alpha$-diol derivatives as well as decreased progesterone $(\mathrm{P})$ metabolites like $5-\alpha, 3 \alpha$, tetrahydro $\mathrm{P} \quad(5 \alpha, 3 \alpha$, THP; allopregnenolone $)$ in addition to simultaneous escalated amounts of substrate precursor pregnenolone [30-32]. In a recent clinical trial a role of neurosteroids in therapy of depression symptoms in cases discussed role of neurosteroids being key in treatment of depression, pointing to a key role of neurosteroids as well as their interactions with neurotransmitter receptors [33]. 
Post-Finasteride Syndrome - When will we Get the Courage to Fight the Dictating Pharma Industry - Despite Awareness of "Sexual, Neurological and Metabolic Side Effects in Young Men for Over a Decade"

Post Finasteride Syndrome (PFS) is a collection of sexual, physicalas well as neurological symptoms which get generated and continue during as well as postfinasteride stoppage (fig2) [34,35]. Of the reported sexual as well as physical side effects correlated with PFS are i) loss of libido, ii) ED; Ejaculatory disorders; iv)reduction in penile sizev) penile curvature vi) decreased sensation vii) gynaecomastia viii) muscleatrophy ix) fatigue $\mathrm{x}$ ) markedly dry skin xi)
Neurological or psychiatric side effects reportedare i) depression as well as anxiety ii)cognitive impairment iii) suicidal ideation [34-53]. Moreover, various case studies have associated finasteride with male infertility [54-57], cataractas well as intraoperative floppy iris syndrome[58], pseudoporphyria [59], as well as T cell-mediatedacute localized exanthematous pustulosis[60].

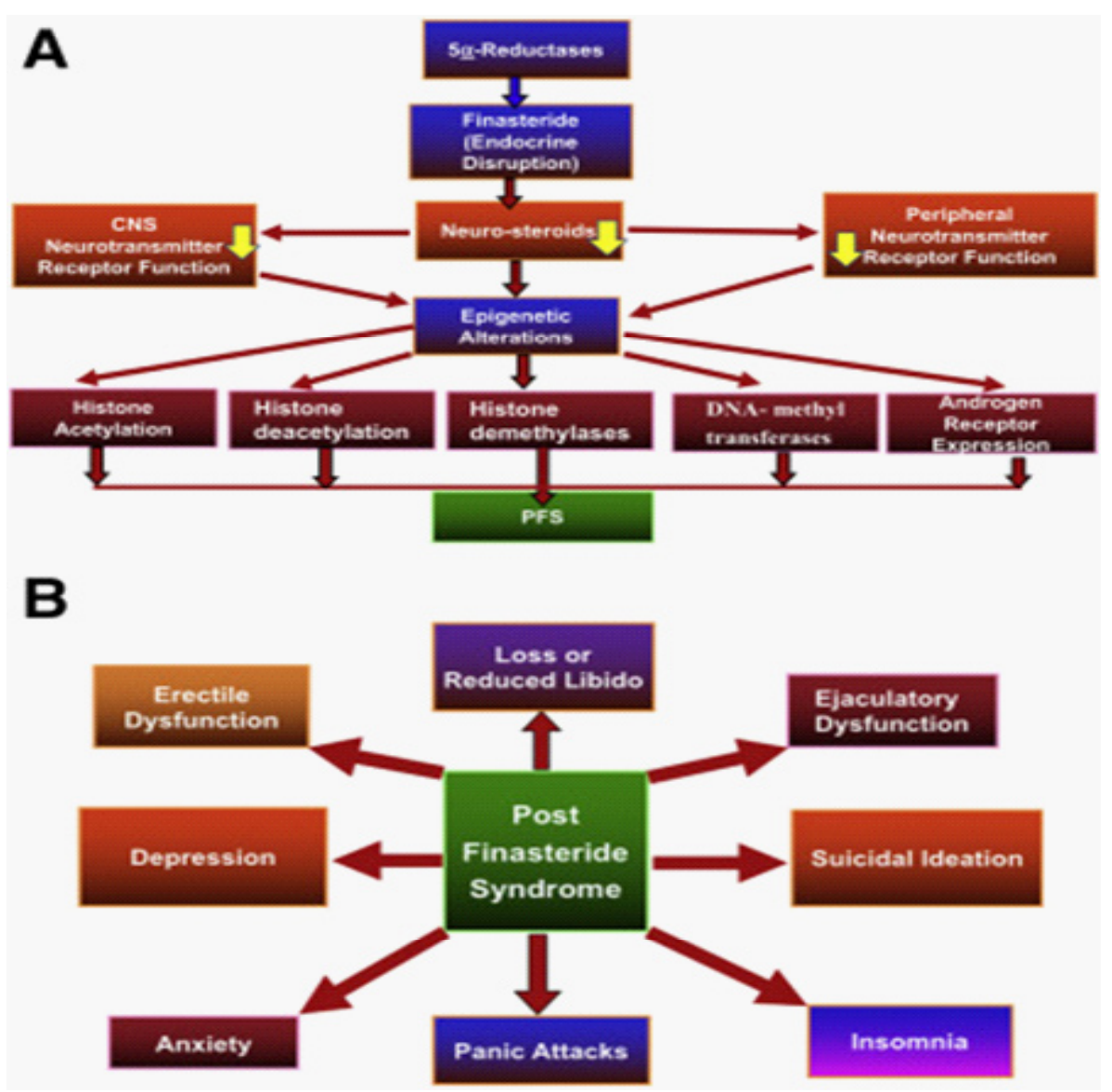

Fig 2. (Courtesy refnumber-47-A) A hypothetical model of finasteride acting as an endocrine disrupter. Finasteride via inhibiting key neuro-steroid biosynthesis promotes epigenetic changes in gene expression leading to silencing or attenuating physiological responses. Inhibition of $5 \alpha$-reductases activities by the high affinity, slow dissociating inhibitor (finasteride) results in depleting the substrate precursors for the $3 \alpha$-hydroxy-steroid dehydrogenases and therefore blocking biosynthesis of neuro-steroids. This inhibition results in attenuating the function of neurotransmitter receptors and promotes changes in the expression of a host of gene products, thus eliciting epigenetic changes manifested in histone acetylation, methylation, and DNA methylation and upregulation of androgen receptor (AR) gene expression. These changes together with depleted neuro-steroid pool manifest itself in the development of PFS in susceptible individuals. (B) The epigenetic changes induced by finasteride elicited endocrine disruption, illustrated in a, produce pathophysiological changes that are manifested as constellations of symptoms of PFS.

(Adapted, with permission from the publisher, from Traish AM. The post-finasteride syndrome: clinical manifestation of drug-induced epigenetics due to endocrine disruption. Current Sexual Health Reports 2018;10(3):88-103.) 
Post-Finasteride Syndrome - When will we Get the Courage to Fight the Dictating Pharma Industry - Despite Awareness of "Sexual, Neurological and Metabolic Side Effects in Young Men for Over a Decade"

\section{METHODS}

We conducted a systematic review and looked in the pubmed search engine along with google scholar for use of finasteride or dutateride in beign prostatic hyperplasia (BPH), androgenic alopecia or post finasteride syndrome using the MeSH terms like finasteride; dutateride; sexual side effects; 'Post Finasteride Syndrome "(PFS); neurological and psychiatric side effects; metabolic side effects from 1970's till date in april 2020.

\section{RESULTS}

We found a total of over 1200 articles out of which we selected 143 articles for this systematic review. No meta-analysis was done.

\section{Sexual Side Effects Revealed by Clinical Studies}

Lot of proofis there that corroborates the presence of a mixed sexual, physical as well as psychological symptoms which form during or following finasteride exposure and continue following drug removal [6164]. Sexual side effects have been documented in practically all studies [10,11, 65 81] Men receiving finasteride or dutasteride in case of $\mathrm{BPH}$ or prevention on prostate cancer occurs $[65,66,68,71,73,76,80$, 81,82-87]. One of the biggest findingon safety of these agentsis escalatedas well as continued sexual dysfunction(reduced or loss of libido, ED as well as orgasmic impairment), irrespective of length of study, drug or dose brought into use. Young men had male pattern of hair loss (AGA) on therapy with finasteride or dutasteride. The commonest side effect seen in this studies were libido loss, ED as well as orgasmic impairment, enhanced anxiety as well as depression along with suicidal ideation [30$32,36,37,39,50,51,54,62,67,88-104]$ Greater than half of these studies were randomised clinical trials. But enough safety testing or documenting was not given in many of these studies. Only occasional studies revealed the methods of evaluation or the scales of questionnaires utilized for testing sexual as well as neurological side effects. In maximum of cases the documenting of any adverse effect was inadequate. Since in most studies sexual side effects revealing was done as for both finasteride or dutasteride by an interview, hence bias got added, knowing that many men don't want to answer questions related to their sexual activities, more so if the interviewer was a female. Whereas some studies have given conflict of interests, about half all studies were funded by the drug manufacturer and in a lot of cases the data management, examining as well as documenting also done by the manufacturer. There may be severe biases in these studies, wrong data reporting and absence of standardized method of side effects evaluation. Observations from these findings were utilized by the clinicians to argue against the presence of Sexual side effects and thus dismiss that any entity like PFS exists.

Findings from systematic reviews as well as metaanalysis as well as pharmacovigilance studies as well as general reviews $[41,44,61,64,74,105-114]$ tried to dismiss the existence of persistent Sexual as well as psychological side effects in some reviews, usual conclusions of maximum of these did address the presence of persistent sexual as well as neurological side effects and emphasized on the requirement of getting more insight of this syndrome so that treatment gets offered to the individual shaving these side effects. Moreover certain studies suggested potential bias presence in many of the reported clinical trials and emphasized the requirement of educating treating doctors for taking these side effects into account with seriousness.

Absence of or decreased libido as well as ED were noted regularly in double blind, randomised placebo controlled trial, along with observational studies. Like in the Corona et al $[110,115]$ studies which was a meta-analysis of 46,733 subjects, it was shown that the chances of ED was enhanced with finasteride. In a meta-analysis of 17 controlled trial conducted by Liu et al[112], where there were 17,494 case analysis of safety was revealed only in 10 trials composed of 6779 patients. They pointed that "The pooled relative risk for sexual dysfunction were 2.56(95\% CI1.48-4.42] in men with BPH as well as 1.21(95\% CI0.85-1.72 in men with AGA; those having erectile dysfunction were $1.55(95 \%$ CI 1.14-2.12) in men with BPH as well as 
Post-Finasteride Syndrome - When will we Get the Courage to Fight the Dictating Pharma Industry - Despite Awareness of "Sexual, Neurological and Metabolic Side Effects in Young Men for Over a Decade"

$0.66(95 \%$ CI $0.20-2.25)$ in men with AGA; as well as those for reduced libido were $1.69(95 \%$ CI 1.03-2.79) in men with BPH as well as $1.16((95 \% \mathrm{CI} 0.50-2.72)$ in men with AGA. Intriguingly, the authors summarized that no associations between finasteride use as well as ED were present. In the same line Hagberg et al.[113] studying a cohort of 12,346 medical records again summarized that no that no associations between finasteride use as well as ED. This was reverse to Corona et al $[110,115]$ studies. What was more significant was the disclosure by Fwu et al. [81] on results of a multicentre, randomised study consisting of 2783 subjects where risk of ED was enhanced with use of finasteride.

Various studies documented that side effects provoked by finasteride, might not resolve following omitting the drug and might become persistent or irreversible in few subgroup of patients [45-50, 57, 58, 85,86]. This might be secondary to susceptibility of these patients to epigenetic predisposition [50]. Men who show symptoms of PFS, about $40.5 \%$ of subjects had problems with erection, while $3.8 \%$ had no erections at all, with other problems being in attaining anorgasmas well as absence of penile sensitivity, reduced ejaculatory force, anhedonia; absence of mental concentration, as well as loss of muscle tone or mass [45-50,57,58,85,86]. Wessels et al's [62] studies that was a 4yrs randomised, double blind, placebo controlled trial, that evaluated the effectiveness as well as safety of finasteride, $5 \mathrm{mg}$ in 3040 men, aged 45-78 yrs and symptomatic BPH, enlarged prostates, with no proof of prostate cancer, they documented that in $1 \mathrm{yr}$ of study, $15 \%$ of finasteride receiving subjects as well as $7 \%$ of placebo treated patients had sexual side effects which were believed to be drug associated $(\mathrm{p}<0.001)$. As per the authors side effects resolved, while continuation of therapy, in $12 \%$ of finasteride receiving subjects as well as $19 \%$ of placebo treated patients Only $4 \%$ of finasteride receiving subjects as well as $2 \%$ of placebo treated patients discontinued the study in view of sexual side effects that was believed to be drug associated $(p<0.001)$. In men who discontinued finasteride in view of sexual side effects, only $50 \%$ of them experienced resolution of these sexual side effects after drug discontinuation. Despite small number of studies claimingtotal reversibility of sexual impairment in all cases following omission of finasteride therapy $[62.63,145]$, rest of the studies discussed patients who had irreversible and continued sideeffects[30-32,34,37,38,39,46-49,50,57,58,84-86]. These observations got corroborated by the results of a retrospective study conducted by Kiguradze et al.[59], where they evaluated data from 11,909 subjects, where 167 subjects were seen to present with persistent erectile dysfunction $(1.4 \%$ of the cohort versus $31.5 \%$ of subjects with therapy related ED).

Depression, Anxiety as well as Suicidal Behavior in Clinical Studies

Atomare G \& Capella GL [95] studied a series of 23 patients comprising of 17 males \& 5 females; having mean age 28.16 years \pm 7.68 standard deviation) who received therapy with finasteride, $1 \mathrm{mg}$ od orally, for AGA. They documented that 19 patients (14males \& 5females) reported mood alterations (moderate to severe Depression at the time of therapy[95]. Depression, markedly had an effect on social relations, sleep, as well as eating behaviour in this group. Irwig and their group documented rates of sexual impairment as well as Depressive symptoms to be significantly > in earlier finasteride users as compared to nonusers, with incidence of moderate to severe Depressive symptoms to be $>$ in finasteride users as compared to nonusers. Suicidal ideation were reported in $44 \%$ of earlier finasteride users while only in $3 \%$ controls $[47,50,51]$. Evaluation of the FDA database (FEARS) showed persistent Suicidal ideation in $7.9 \%$ of males [84].

\section{Etiopathogenesis of Erectile Dysfunction}

Different possible modes explain the persistent sexual impairment felt following finasteride use or that of dutasteride. These are inhibition of steroidogenesis, changes in neural network structure as well as function and changed blood vessel, smooth muscle cell atrophy as well as fibrosis of erectile tissue (fig3). That 5- $\alpha$ DHT has a critical role in erectile physiology is significant $[10,11,74-76]$. Hence, inhibition of $T$ 
Post-Finasteride Syndrome - When will we Get the Courage to Fight the Dictating Pharma Industry - Despite Awareness of "Sexual, Neurological and Metabolic Side Effects in Young Men for Over a Decade"

conversion to $5-\alpha$ DHT(fig1) by finasteride as well as dutasteride mighteffect the erectile physiology. Pinsky et al. [14] as well as Oztekin et al. [15] [15]showed that treating mature intact animals with the 5-alpha reductase inhibitor (dutasteride, lead to marked decrease in the expression of as neural (nNOS) nitric oxide synthases (fig4) as well as loss of trabecular smooth muscle as well as marked escalation of connective tissue deposition(fig4) causing poor tissue compliance as well as ED. This pathology ended in blunting of the in vivo erectile response, despite drug discontinuation[15]. Evaluating the long term effects of finasteride therapy on erectile function in mature intact male animals for 16 wks with a daily oral dose of $4.5 \mathrm{mg} / \mathrm{kg}$ Zhang et al.[13]corroborated the observations of Pinsky et al.[14] as well as Oztekin et al. [15]regarding marked amelioration of penile erectile response in vivo to electric field stimulation (EFS)of the cavernosal nerve with simultaneous loss of trabecular smooth musclecontentas well as escalated connective tissue deposition. Further at a greater degree the expression of endothelial nitric oxide synthases ((eNOS) was markedly ameliorated by finasteride therapy resulting in erectile dysfunction.

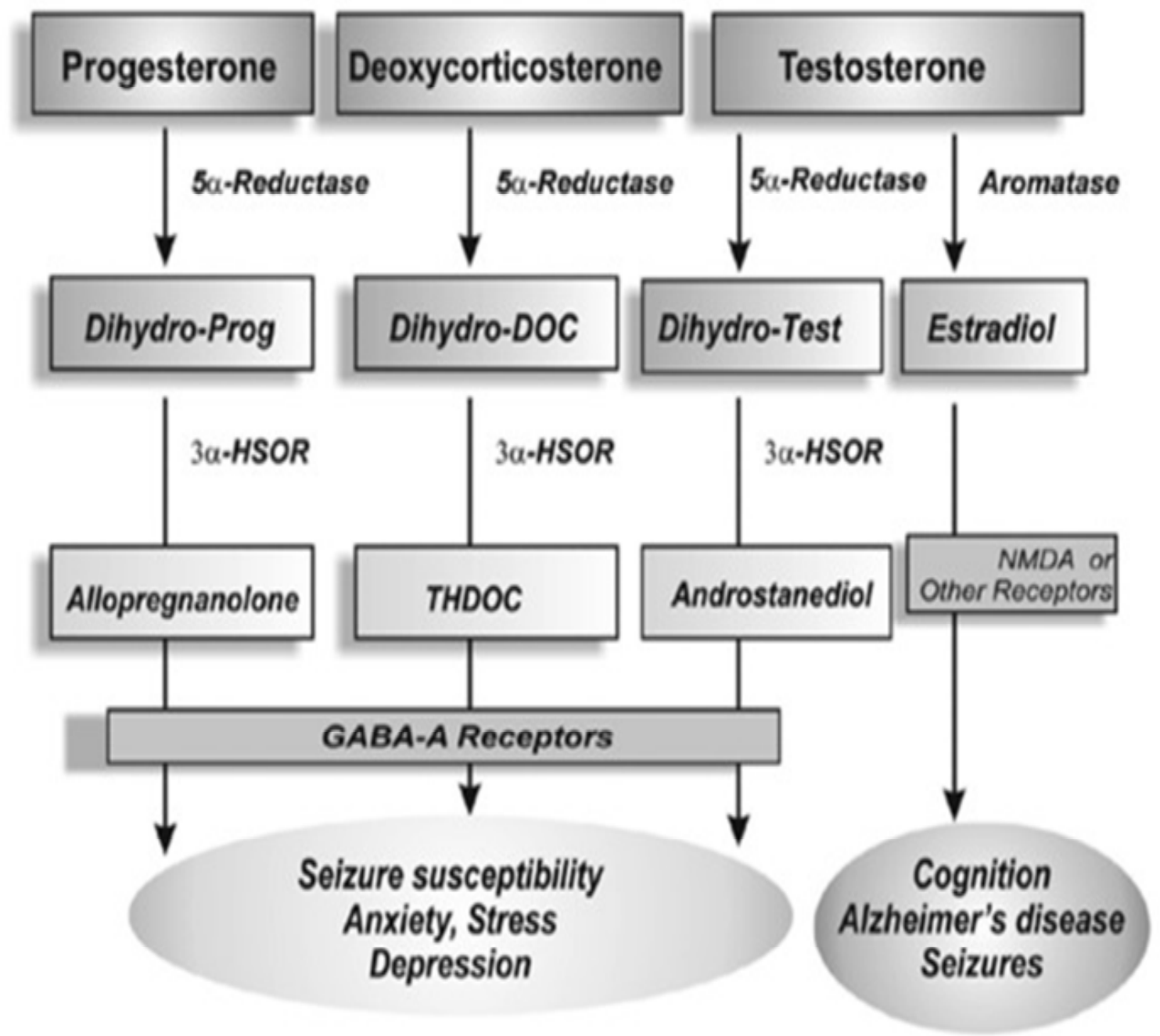

Fig 3. Courtesy ref number-47-Biosynthetic pathways of neuro-steroids in the human brain and their impact on brain function. $5 \alpha$-Reductase converts progesterone, testosterone and deoxycorticosterone into 5 $\alpha$-dihydro reduced steroids, which are then reduced further to $3 \alpha$-hydroxylated neuro-steroids by $3 \alpha$-HSOR. Testosterone is converted into $17 \beta$-estradiol by the aromatase enzyme. These and related enzymes involved in neuro-steroid biosynthesis and metabolism are present in the human brain. 
Post-Finasteride Syndrome - When will we Get the Courage to Fight the Dictating Pharma Industry - Despite Awareness of "Sexual, Neurological and Metabolic Side Effects in Young Men for Over a Decade"
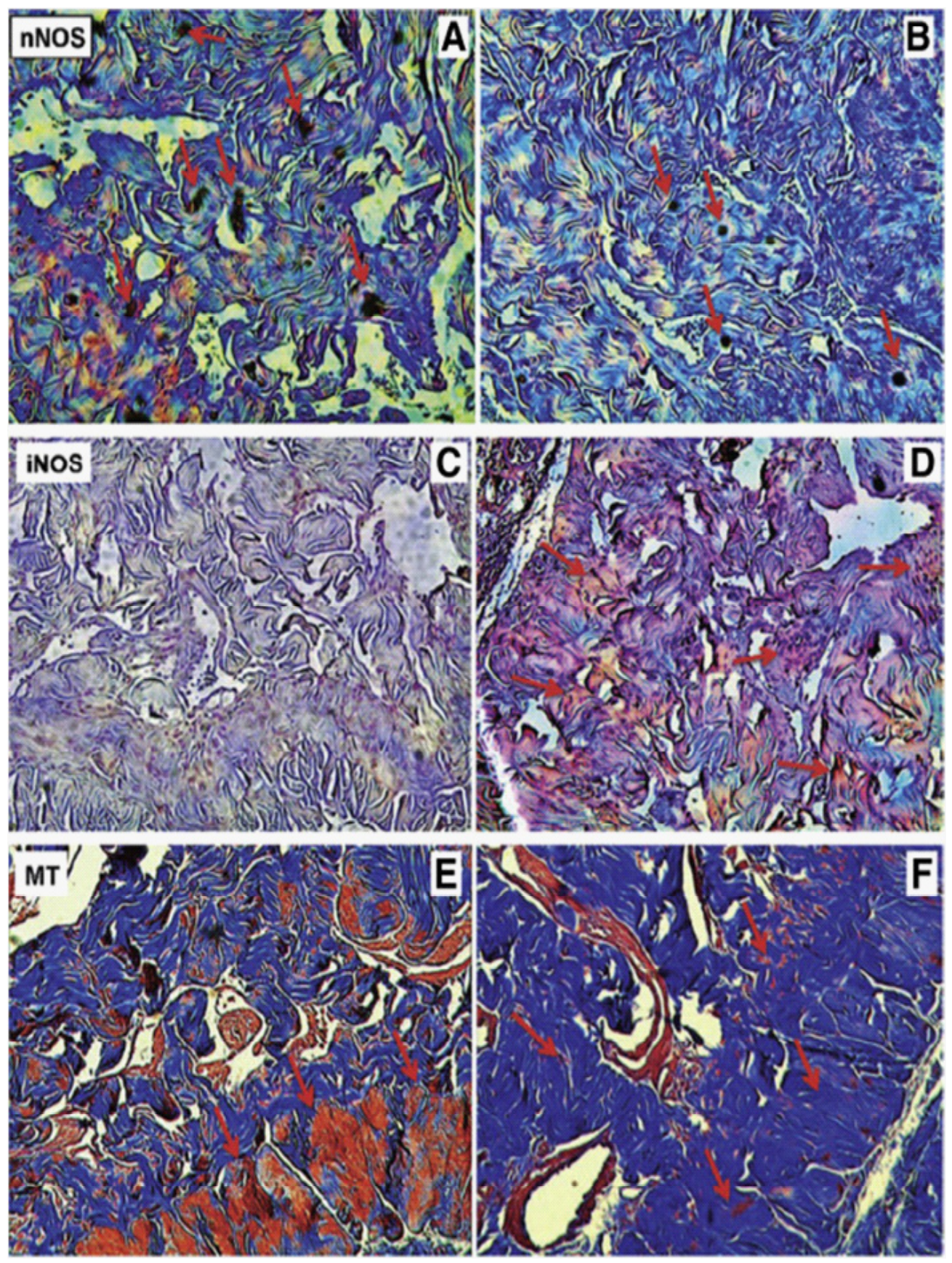

Fig 4. Courtesy ref number -47-Effects of chronic treatment of animals with Dutasteride on the expression of eNOS, iNOS and trabecular smooth muscle content in the adult male rat. Immunohistochemical localization of nNOS and iNOS in rat penis (40× magnification). (A, B) nNOS staining (dark brown) with decreased localization to the nerves of the corpus cavernosal smooth muscle from control $(A)$ to treatment $(B)$ groups. $(C, D)$ iNOS staining (dark brown) enhanced in the corpus cavernosal smooth muscle from the treatment group. The negative control section processed without antibodies did not stain (data not shown). (E, F) Masson's trichrome (MT) staining results. MT staining is presented as ratio of smooth muscle: collagen in a percentage (mean \pm standard deviation), which is markedly different between control (E) and treatment (F) groups. Quantitative analysis of collagen, and smooth muscle content in cavernosal tissue was performed with an image analyzer. nNOS = neuronal nitric oxide synthase; iNOS = inducible nitric oxide synthase. 
Post-Finasteride Syndrome - When will we Get the Courage to Fight the Dictating Pharma Industry - Despite Awareness of "Sexual, Neurological and Metabolic Side Effects in Young Men for Over a Decade"

Etiopathogenesis of Depression, Anxiety as well as Suicidal Behavior

With finasteride therapy neurosteroids biosynthesis gets inhibited that are believed to be key controllers of CNS[12-15], along with peripheral nervous system functions, as they manipulate neurotransmitter receptor functions, like gamma amino butyric acid receptor s(GABA-R) (fig 5), showing the significance of these physiological manipulation in causing depressive symptomatology. Hence inhibition of allopregnenolone biosynthesis might be responsible for anxiety as well as depression in patients of PFS. Basaria et al. [39] used functional MRI that corroborated anomalies in brain regions that are directly implicated in depressive symptom as well as sexual arousal, like nucleus accumbens as well as prefrontal cortex. Melcangi et al. [32] further corroborated decreased neurosteroids levels as well as nerve neuropathy in the group of PFS patients of which 10 revealeda severe ED, whereas 6 showed a mild-moderate ED. Furthermore they demonstrated an objective proof regarding peripheral neurogenic regulation of erection being involved in case of finasteride studies. Actually abnormal somatosensory evoked potentials of the pudendal nerve was observed in 4cases who demonstrated a DSM-IV major depressive3 disorder akin to that shown by Basaria et al.[39].

\section{Those Against PFS}

Lots of reports pointed that utilization off finasteride in the therapy of BPH along with AGA was thought to be safe as well as tolerable, with minimal or no side effects seen [30-32,36,37,39,47,49,53,63,66-68,71, $72,73,76,80,81,82-104]$.

This is just the reverse of results got through metaanalysis or pharmaco vigilance studies, where sexual as well as neurological side effects were thought to be there $[61,74,104,112,115]$. Longitudinal evaluation of sexual function showed by men in the prostate cancer prevention trial[84] had an altercation that the low sexual side effects that resolved following persistent therapy, did not call for there being serious side effects and did not agree with the presence of PFS .Moreover Mella et al.[105] furthered their belief saying only very minimal reduction in erectile function was reported with finasteride therapy as compared to placebo arm and a very small percent(2\%- 7\%)of subjects had ED, and thusto label these symptoms as PFS is unwanted.
As per Fertig et al. $[63,64]$ on reviewing the side effects of finasteride, summarized that continuous sexual as well as psychiatric side effects following 5 - $\alpha$ reductase inhibitor ( $(5-\alpha-\mathrm{RIs})$ were not shown by studies that were of best quality and hence there is no space for PFS in clinical scenario as far as reproductive medicine is concerned.

Lot of clinical trials regarding finasteride, had no spontaneous documenting along with quantitative as well as scales that had been approved for checking decrease in sexual function. Like till recently, most of earlier trials did not use the international index of erectile function (IIEF) questionnaire, that has been demonstrated to be the standard regarding evaluation of sexual dysfunction. Hence it is thought that those studies had marked problems as far as the methodology as well as interpretation was concerned as well as incorrect reporting. Like Belknap et al's [61] detailing, one of the botherationis that the outcome on side effects might not have been collected scientifically and lot of reliance was on self reporting and hence one can't rely on those data. Moreover other confounding variables like studies of short duration .Patients loss during follow up and absence of documentation on persistent side effects makes the implications made in these reports to be queried.

\section{Advocates of PFS}

Lot of studies gave proof stressing on escalated rates of sexual dysfunction in case of men presenting with $\mathrm{BPH}$ as well as AGA receiving finasteride therapy [46$50,52,53,55,56,58,59,60-62,67-72,74,75,83,84,89,127$ $129,139,145,150,183-186]$. Like current studies by Basaria et al [39] documented men who stopped finasteride therapy and kept on experiencing sexual side effects. These men had a < IIEF scores, <vaginal penetrations, <sexual desires, as well as very bad ejaculatory function as well as <satisfaction at coitus. On examining mood as well as Depression, on the basis of granular as well as minimal fMRI evaluation, abnormalities in the brain areas of symptomatic users of finasteride before were possibly those patients picked up with psychogenic erectile dysfunction. As these patients did not have a fMRI before finasteride therapy, one can't say definitely that these abnormalities were secondary to finasteride therapy. Still this study verified that a subgroup of men who received finasteride therapy as well as omitted it 
Post-Finasteride Syndrome - When will we Get the Courage to Fight the Dictating Pharma Industry - Despite Awareness of "Sexual, Neurological and Metabolic Side Effects in Young Men for Over a Decade"

remained affected by persisting sexual side effects. Rahimi-Ardabili et al [53] documented results of 128 men presenting with AGA receiving $1 \mathrm{mg}$ finasteride therapy. They found that depressed mood as well as anxiety was received by Beck Depression Inventory (BDI), as well as Hospital Anxiety and Depression Scale (HADS). The subjects finished BDI as well as HADS questionaire prior to initiation of therapy as well as $2 \mathrm{mth}$ following it. At baseline (mean SD) BDI as well as HADS Depression scores were $12.11( \pm 7.50)$ as well as 4.04( \pm 2.51$)$ respectively. Finasteride therapy escalated both BDI $(p<0.001)$ as well as HADS Depression scores significantly $(\mathrm{p}=0.005)$. They indicated that finasteride therapy might stimulate development of depression symptoms. Melcangi et al. [32] revealed that patients with PFS demonstrated changes in amounts of Neuroactive steroids that are thought to be significant physiological controllers of brain function. This might in part explain the psychiatric features seen in PFS patients. These biochemical changes might effect dopaminergic signalling in the nucleus accumbens and lead to the side effects seen In an observational study Chiriaco etal.[89] studying 79 young men ( $>18 \mathrm{yrs}$ and $<50$ yrs old)that used finasteride therapy for AGA for mation had persistent long term adverse effects for a minimum of $6 \mathrm{mths}$ following drug omission. Patients got registered 180-5057 days following the drug omission. In all their patients side effects continued for $6 \mathrm{mthsfollowing} \mathrm{the} \mathrm{drug} \mathrm{omission} \mathrm{and} \mathrm{were} \mathrm{still}$ continuing when they got registered for the study. In $89.9 \%$ of the patients who took partsymptoms onset took place during finasteride use with the pattern of symptoms worsening in $62 \%$ on the basis of the ad hoc questionnaire, the commonest symptom being absence of penis sensitivity in $87.3 \%$, of the mental problems decreased appreciation of life pleasures or emotions (anhedonia) occurred in $75.9 \%$ and regarding somatic symptoms loss of musclemass or tone occurred in $51.9 \%$.

Kiguradze et al.[62] questioned an electronic medical record(EMR) database from a large urban, academic medical centre in Northwestern University in Chicago for verifying healthy men who had Sexual dysfunction following finasteride therapy. They looked in the EMR database of about 2.9 million individual records from January 2001to September 2013. They founda cohort of healthy men $<42$ yrs age $(n=4274)$ following finasteride therapy exposure at a dose $<1.25 \mathrm{mg} /$ day and without exposure to other 5 - $\alpha$ reductase inhibitors other than finasteride. Significantly, these men did not have any Sexual dysfunction before finasteride therapy exposure and no earlier phosphodiesterase type -type 5 inhibitors (PDE-5) use. They utilized ICD-codes for picking uperectile dysfunction as well as low libido along with confirming with the manual review of the EMR. Further they picked up new onset Sexual dysfunction as new erectile dysfunction, low libido or PDE-5 use for erectile dysfunction treatment. More significantly, they defined Persistenterectile dysfunction or low libido remaining for $>90$ days following finasteride omission. They documented 47 patients who experienced Persistenterectile dysfunction with median duration of Sexual dysfunction after termination of finasteride was 1398 days and Persistent $>365$ days was present in 36/270 persons (13.3\%). The most amount of Persistance was 3356 days.

Ali etal. [88] observed that in 4910 reports, 577 showed Persistent Sexual dysfunction and 39 showed suicidal ideation. In $34(87.2 \%$ of the $39 \%$ men with suicidal ideation also experienced Sexual dysfunction. Most of these symptoms were serious (like lead to patients death, hospitalization, or disability). They concluded finally that Persistent Sexual dysfunction is a potentialrisk of finasteride for AGA therapy in young men, and this risk aids in suicidal ideation. Ganzer et al. [36,37] revealed Sexual dysfunction in 131 men who were on finasteride therapy, that included libido alteration, loss of morning erections, erectile dysfunction as well as anhedoniain sex. Reduction in sexual drive was observed in 121 men (93\%); complete sexual drive loss in 82men(63\%); intermittenterectile dysfunction in 108men (83\%); total impotence in $52 \mathrm{men}(40 \%)$; loss of morning as well as spontaneous erections in 116men(89\%); inability to achieve orgasm on maximum times in 52 men (40\%); anhedoniain sex, loss of pleasurable orgasm in 91 men(70\%). Choi et al[91] revealed that110 patients with AGA getting treatment with dutasteride, 7 patients felt erectile dysfunction. Of these only 3 said that their erectile dysfunction resolved. While in other 3 ED remained unresolved and 1 remains with unknown results.

In the same line Tsunemiet al, [124] documented that AGA patients who got treatment with dutasteride had Sexual dysfunction adverse events (SADE) as the commonest side effects. A t 1 Yr 3 patients documented 
Post-Finasteride Syndrome - When will we Get the Courage to Fight the Dictating Pharma Industry - Despite Awareness of "Sexual, Neurological and Metabolic Side Effects in Young Men for Over a Decade"

events that were probably suicidal - associsated. They summarized that all documented SADE of special significance were possibly drug - associated, other than 1 case of impotence. SADE documented in 6 patients got resolved during 52 wk therapy duration. The rest 13 patients with SADE which continued at the end of therapy duration of 1 yr got resolved within the $6 \mathrm{~m}$ th follow up time after therapy omission [124]. Guo et al. [90] found 1390 men who had been using finasteride and contrasted them with 20,000 users of omeprazole. As omeprazole does not cause Sexual dysfunction it was used to compare. They observed that the median duration to $1^{\text {st }}$ Sexual dysfunction following cessation was 339 days. The rate of persistent Sexual dysfunction for $1 \mathrm{mg}$ finasteride users as well as users of omeprazole were 37.9 as well as $15 / 1000$ person yrs, respectively. The rates as well as Hazard ratios of persistent Sexual dysfunction of users in the primary evaluation of persistent Sexual dysfunction defined as the $1^{\text {st }}$ Sexual dysfunction code were 2.19 (crude) and 1,62(adjusted)for finasteride comparedto 1 in the omeprazole. In the secondary evaluation of the persistent Sexual dysfunction defined as the use of PDE-5,the crude as well as adjusted Hazard ratios were 2.41 as well as 2.73 , respectively, pointing to a significantly enhanced risk of persistent Sexual dysfunction with finasteride.

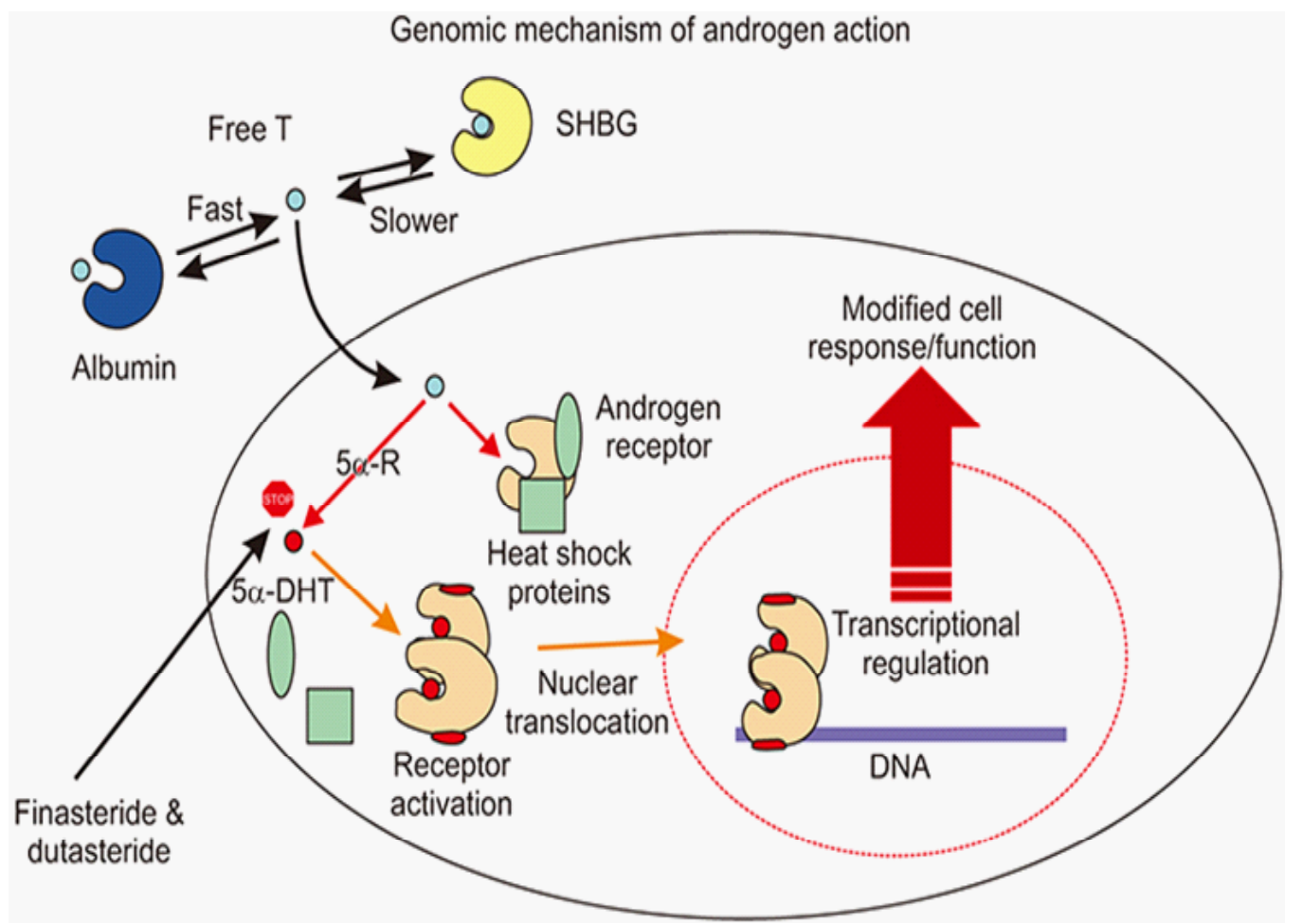

Fig 5. Courtesy ref no-143- Universal genomic molecular mechanism of androgen action. One key biochemical reaction in this sequence of pathways is the transformation of testosterone (T) to $5 \alpha$ - dihydrotestosterone ( $5 \alpha$ DHT) via $5 \alpha$-reductases ( $5 \alpha-R s)$. This pathway is critical in the function of androgen receptor, since $5 \alpha$-DHT is more potent natural ligand than T. SHBG: sex hormone binding globulin.

\section{DiscuSSION}

Till recently the side effects of finasteride as well as dutasteride therapy on Sexual function were not realized or properly understood. But a lot of proof points that evaluation of Sexual side effects of finasteride in a lot of clinical studies were not actually picked up or documented[61]. Moreover lot of bias as well as inconsistencies in documenting the side effects of finasteride as well as dutasteride in most clinical trials of mentreated for AGA by Belknap et al[61]. Then an editorial subsequent to this report by Belknap et al[61], emphasized on the requirement of re evaluating about the safety of these drugs by Wessels et al.[66].

It is not astonishing that practically all studies did report escalated sexual side effects. But despite that 
Post-Finasteride Syndrome - When will we Get the Courage to Fight the Dictating Pharma Industry - Despite Awareness of "Sexual, Neurological and Metabolic Side Effects in Young Men for Over a Decade"

the number of patients affected being small, it was propagated that these sexual side effects do resolve with continuation of therapy. Unfortunately this has been done knowingly putting a blind eye and keep prescribing these drugs to unsuspecting young men has continued. The total number of patients involved is neither small nor unimportant, having the insight now that there is persistent of these side effects. For those individuals affected it constitutes literally as a life sentence of Sexual dys function, depression as well as or anxiety. Roughly 30 million young men worldwide would get finasteride as well as dutasteride prescribed for therapy of male pattern hair loss if seen in long term perspective. Assuming the incidence of persistent sexual side effects is $3 \%-5 \%$ that might be looked and even in small numbers, roughly 900,000 to1, 5 million men would undergo persistent sexual as well as psychiatric side effects. These are not a small numbers by any set of imagination and can't be simply dismissed.

The crucial explanation given by a lot of doctors is that how much is the degree of proof to corroborate the persistent type of sexual side effects as well as psychological symptoms that finasteride causes? In the contemporary literature there has been lot if work showing the physiological part of 5- $\alpha$ reductases in the peripheral tissues as well as CNS along with the etiopathological hint of trying to inhibit these enzymes and thus interfering with the biosynthesis of neuroactive steroids, that are key biological modulators in the CNS and are responsible for the mood changes, cognition alterations, as well as libido [23-50]. Further a lot of preclinical proof is there showing that inhibition by5- $\alpha$-RIs leads to ED [12-15] and might also aid in neurological symptoms development (fig1,3,4][25]. Various studies along with data from manufacturer itself show that certain side effects occur which do not resolve on drug cessation as well as in certain cases they persist or become irreversible $[7,10,36,37,49,5$ $0,61,62 \cdot 66,81,88,89,90,110,123-125]$. Thus in view of this Traish [47] point that there is resolution of sexual side effects is outrageous and misleading.

The >documentation of persistent sexual side effects in the clinical publications lead to issuance of warnings by the Medicine Health Care Products Regulatory Agency (MHRA) public evaluation report on the risk of finasteride published in December of 2009 in Section
4.8 Undesirable Effects it was said that "In addition, the following have been reported in post marketing use: persistence of ED following discontinuation of therapy with PROPECIA". Hence it is very obvious that the sexual side effects do not resolve totally in all patients, who omit use of finasteride, that again corroborate this statement that sexual side effects remain "persistent". Moreoverin Dec 2008, theSwedish medical products agency finished its safety evaluation of propecia. The Agencies updated safety information has a list $\mathrm{z}$ now of possible side effect problem in getting an erection which persists following cessation of propecia. Additionally in 2011, the USA FDA made it compulsory that finasteride labeling has information regarding potential chances of depression as well as Sexual dysfunction as well as chances of high grade prostate cancer. In 2017, European Medical Agency recommended adding depression as well as suicidal ideation on the finasteride label.

One more altercation in literature has been that low quality proof do not corroborate a causative link among finasteride as well as persistent symptoms. Looking at all of the contemporary clinical literature, it seems that practically all studies that have been published till date pointed escalated onset of Sexual dysfunction as well as psychiatric dysfunction, without bothering about the evaluation method, age, drug or dose. One needs to query how can such proof be totally sidelined and dismiss it as low quality evidence? Knowing that a lot of bias is inserted in these studies as lots of clinical trials were funded as well as administered by manufacturers themselves, it is of extreme significance that clinicians use their own judgement and not fall in the trap of "these drugs are well tolerated and safe".

Hence it has become essential that we as clinicians need to take into account how badly documenting of side effects secondary to finasteride as well as dutasteride have been incomplete in maximum clinical trials [61,62]. Actually this incomplete documenting of side effects makes the proof as far as the evidence is concerned limited and they may seem to be of poor quality. Knowing the amount of bias secondary to vested interests, it is not at all astonishing that the degree of harm has been significantly tampered with. Clinicians that have received good training and have enough experience might realize the co presence of these side effects in the form of a proper separate syndrome having its own pathogenesis instead of 
Post-Finasteride Syndrome - When will we Get the Courage to Fight the Dictating Pharma Industry - Despite Awareness of "Sexual, Neurological and Metabolic Side Effects in Young Men for Over a Decade"

simply random or sudden coexistence. Inspite of absence of evidence the mere presence of persistent as well as severe side effects that are stimulated via these drugs increases marked concerns for these doctors. Just the low tested prevalence of PFS need not be utilized as an excuse for non awareness, having the knowledge that these drugs are going to be written for millions of relatively men who are young and healthy.

Though these botherations as far as finasteride side effects were concerned initiated the NHS to add PFS to the Genetic as well as Rare Disease Information Center, PFS still is not recognized by the medical personnel, despite multiple patients presenting with literally markedly severe, odd as well as classic symptomatology. It really is bothering that a lot of doctors as well as crucial opinion incharge people from different clinical areas keep on arguing and ignoring any idea that, PFS is an actual syndrome instead of figment of imagination [44-46,60,64,66-68, 93,82,83,72, 94, 95, 96, 97, 98, 99, 101, 102, 104, 106, 111, 112, 113, 119,122,126-130]. More distressing is that these doctors actually put a label of patients having PFS as being unstable, delusional or psychotic $[45,46$,$] .$

It is very simple to keep dismissing the new findings in science as well as a medicine in both clinical as well as a scientific literature. One anticipates that it would be good enough that despite limited proof, it would not be acceptaple to totally ignore PFS as well as prevent the affected patients a minimal thorough examination as well as proper therapy, if present. The occurrence of tardive dyskinesias secondary to phenothiazine utilization in the therapy of patients having chronic schizophrenia are well recognized [131-138]. In the same line long QT syndrome (LQTS) [134-138], Brugada Syndrome [136] as well as Fanconi syndrome[138]. In contrast to PFS, persistent side effects secondary to therapy with other drugs are well accepted and picked up[131-138] whereas the persistentside effects due to finasteride therapy get denied venomously.

Once other Drug induced syndromes, other than that of finasteride get well accepted by the medical union, it puts up a basic query why is there so much fight by the medical physicians in accepting as well asgiving recognition to PFS? Recently Maksym et al.[43] on reviewing the literature on PFS said that even in absence offinal evidence for PFS, the mere presence of severe as well as persistent side effects secondary to therapy of AGA increases grave concerns for the clinician. Just the low calculated prevalence of PFS can't be made the grounds for not bothering in view of millions of young as well as healthy persons are going to consume it. As imaging reports from earlier finasteride users got from Basaria's [39] fMRI studies as well as neurosteroid amounts in CSF by HPLC-Mass spectrometry evaluation [30-32] suggest that interference with neurotransmitters as well as chemical messengers via finasteride, one can't keep fighting regarding safety as well as tolerability of these drugs. Dismissing of this syndrome is like putting a blind eye to what is glaring for the whole medical group, in total.

The commonest reasoning offered is why only some patients influenced while no effects in others. There might be an epigenetic susceptibility of few individuals to development of side effects [34]. Intriguingly with so many drug induced syndromes that have got the recognition of these medical community [132-138], it is astonishing that PFS seems to beso problematic in getting recognition.Then the query comes up why so much fierce and persistent resistance?

It is totally clear to us that risk of bias comes from different quarters, that include randomised controlled trials (RCT)[ [61,66,139140], knowing that maximum of finasteride or dutasteride trials got support as well as got managed by their manufacturers having conflict of interest obviously. Maximum times evaluation for harm in clinical trials is not mostly told in any publicly available documentation. In view of that, at best one has to be alert regarding the outcome of these clinical trials that might have done underreporting of the side effects be it of finasteride or dutasteride. As documented by Belknap et al.[61], absence of information regarding harm is usually what happens in published trials and thus meaningful evaluation can't be done and hence proof might appear queried. Side effects produced by drugsin RCT's are not systematically examined with the quality, scientific vigor as well as objectiveness available for evaluation of drug beneficiality. As shown by Golder et al[139] as well as Kaptchuk et al[140] not full data of clinical trials can be totally correct and absolutely reproduced unequivocally and thus deep evaluation of the data 
Post-Finasteride Syndrome - When will we Get the Courage to Fight the Dictating Pharma Industry - Despite Awareness of "Sexual, Neurological and Metabolic Side Effects in Young Men for Over a Decade"

reported as well as better evaluation of reported data is needed for arriving at a real evidence dependent approach to find the extent, degree as well as scope of sexual side effects. All these limitations should not deter in getting insight of this complicated syndrome alias PFS.

One can't label our patients delusional or psychotic $[45,46]$, in view of our failure to get insight into pathophysiology. Moreover lot of proof of 5 - $\alpha$-RIs on sexual function [12-15] as well as actions on CNS might offer reason for side effects in mood, anxiety as well as depression [43]. Moreover newer studies have shown that these drugs increase incidence of type 2diabetes mellitus( DM)[141] as well as renal disease[142], reviewed by Traish [143], along with
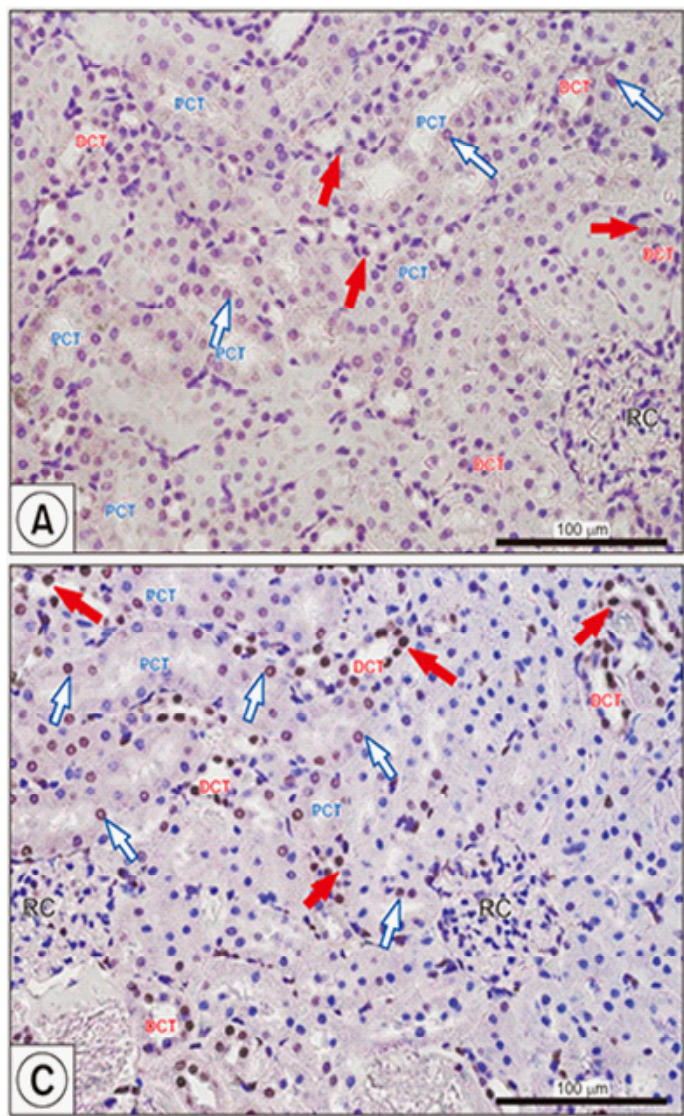

lacrimatory glands(fig 6,7). Due to these we need to be more cautious regarding harm done by these drugs. Hence with obvious symptoms to totally negate the harm caused by these drugs is not appropriate. Doing this just reflects on the false ego of the clinical community lacking insight into the pathophysiology.

Time has come to accept these obvious clinical symptoms and give recognition to this syndrome instead of label our patients delusional or psychotic $[45,46]$, it seems we are delusional or psychotic doing knowing harm or closing eyes to overt symptomatology. We need to train our youngsters for having greater insight and start understanding mechanisms causing PFS along with its progression.

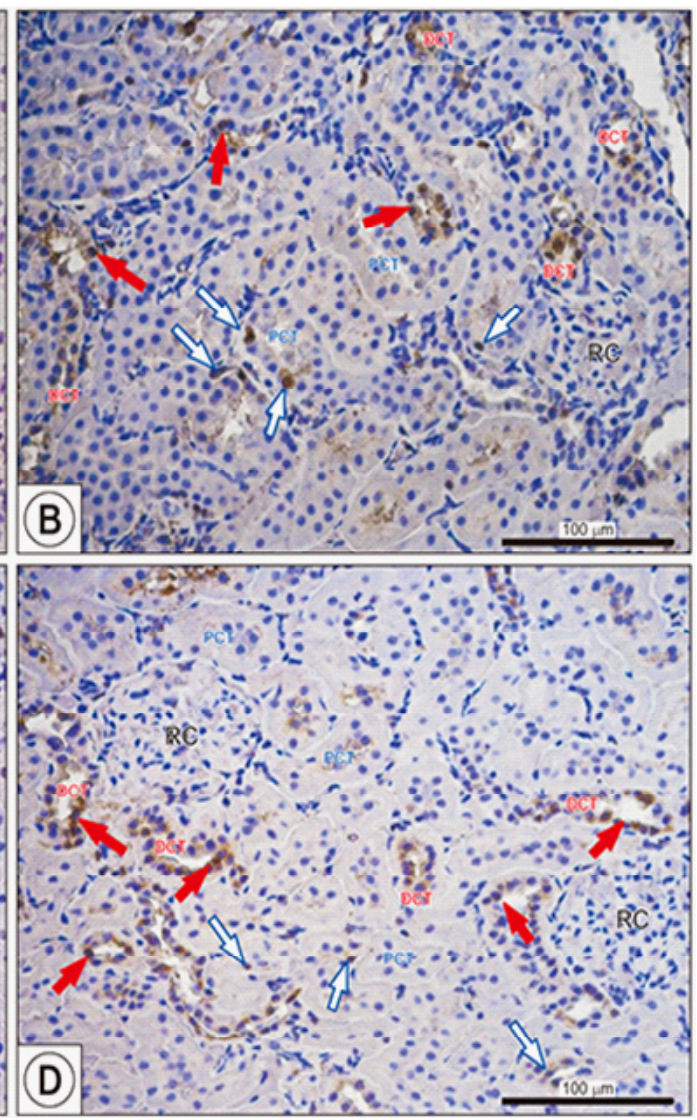

Fig 6. Courtesy ref no-142Representative microphotography showing terminal deoxynucleotidyl transferase dUTP nick end labeling reaction $(A, C)$ and proliferating cell nuclear antigen-positive cells $(B, D)$ in control $(A, B)$ and finasteride-treated $(C, D)$ rats. Red filled arrows indicate positive signaling in nuclei of proximal convoluted tubule (PCT); blue empty arrows indicate positive signaling in nuclei of the distal convoluted tubule (DCT). Slides were rinsed in phosphate buffer saline and labeled with streptavidin conjugated with horseradish peroxidase. To visualize the effect of the reaction (places of DNA split), 3,3'-diaminobenzidine was added. Positive staining was defined microscopically (Leica DM5000B, Germany) through visual identification of brown pigmentation of the cell nucleus. Scale bar from objective magnification $\times 40(A, B ; C, D)$ is $100 \mathrm{~mm}$. RC: renal corpuscle. 
Post-Finasteride Syndrome - When will we Get the Courage to Fight the Dictating Pharma Industry - Despite Awareness of "Sexual, Neurological and Metabolic Side Effects in Young Men for Over a Decade"
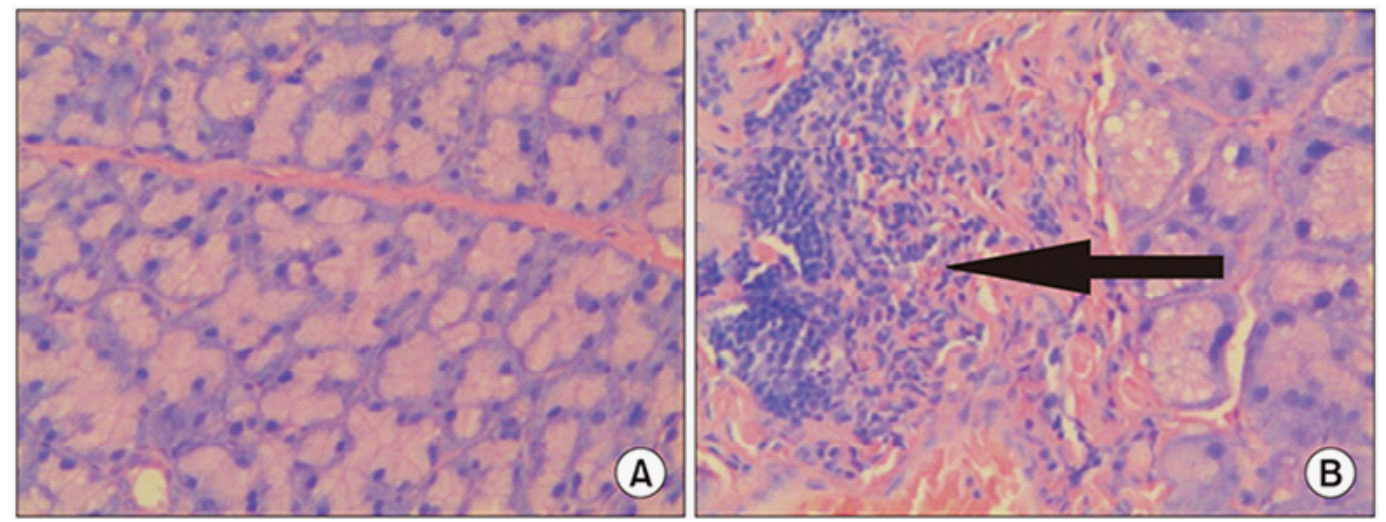

Fig 7. Courtesy ref no-142- Lacrimal gland histopathology (H\&amp;E, ×400). (A) Lacrimal gland from the control group; (B) Lacrimal gland from the oral finasteride group. A large number of lymphocytes had infiltrated the interlobular space and surrounded the acinar and ductal cells as indicated by the black arrow.

\section{CONCLUSIONS}

Thus in this systematic review we have described the physiology along with pathophysiology that explains how PFS develops secondary to use of 5 alpha reductase inhibitor(5- $\alpha$ RI) like Finasteride and dutasteride for BPH or APA or male pattern loss. Both strong points for accepting this syndrome has been described. It is time to appreciate this syndrome and not keep labelling the men who complain of Persistent sexual dysfunction or psychiatric side effects as psychiatric or delusional. Hopefully soon our medical community accepts and makes our youngsters realize the gravity of these serious side effects.

\section{REFERENCES}

[1] Imperato-McGinley J, Guerrero L, Gautier T, Peterson RE. Steroid 5-alpha reductase deficiency in man: an inherited form of male pseudohermaphroditism. Science 1974;186:1213-5.

[2] Imperato-Mc Ginley J. 5-alpha reductase-2 deficiency and com plete androgen insensitivity: lessons from nature.Adv Exp Med Biol 2002;198:51-9.

[3] Imperato-Mc Ginley J, Zhu S. Androgens and male physiology the syndrome of 5-alpha reductase deficiency.Mol Cell Endocrinol 2002;198:51-9.

[4] Sasaki G, Ogata T, Ishii T, Kosaki K, Sato S, Homma $\mathrm{K}$, et al. Micropenis and the 5-alpha reductase -2(SRD 5A2) gene mutation and $V$ 89L polymorphism:analysis in 81 Japanese patients.J Clin Endocrinol Metab 2003;88:3431-6.
[5] Katz MD, Kligman I, Cai LQ Zhu YS, Frattiani CM, Zervoudakis I, et al. Paternity by intrauterine insemination with sperm from a man with 5-alpha reductase 2deficiency.N Engl J Med 1997;336:994-7.

[6] Russell DW, Wilson JD. Steroid 5-alpha reductase/2 genes/two enzymes. Ann Rev Biochem 1994;63:25-61.

[7] Traish AM, Hassani J, Guay AT, Zitzman M, Hansen ML. The dark side of 5-alpha reductase inhibitor's therapy:sexual dysfunction, high Gleason Grade prostate cancer and depression. Korean J Urol 2014;55:367-9.

[8] Traish AM. 5-alpha reductase in human physiology:an unfolding story.Endocr Pract 2012;18:965-75.

[9] Traish AM., Haider KS, Doros G, Haider A. Finasteride, not tamulosin, increases severity of erectile dysfunction and decreases testosterone levels in men with benign prostatic hyperplasia.. Horm Mol Biol Clin Investig 2015;23:85-96.

[10] Traish AM, Melcangi RC, Bortolato M, GarciaSegura LM, Zitzman M.Adverse effects of 5-alpha reductase inhibitor's: what do we know, don't know, and need to know?Rev Endocr Metab Disord 2015;16:177-98.

[11] Traish AM, Haider KS, Doros G, Haider A.Long term dutasteride therapy in men with benign prostatic hyperplasia alters glucose and lipid profiles and increases severity of erectile dysfunction. Horm Mol Biol Clin Investig 2017;30: 
Post-Finasteride Syndrome - When will we Get the Courage to Fight the Dictating Pharma Industry - Despite Awareness of "Sexual, Neurological and Metabolic Side Effects in Young Men for Over a Decade"

[12] Lugg JA, Rajfer J, Gonzalez-Cadavid NF. Dihydrotestosterone is the active androgen in the maintenance of nitric oxide-mediated penile erection in the rat.Endocrinology 1995;136:1495-501.

[13] Zhang MG, Wang XJ, Shen ZJ, Gao PJ.Long term oral administration of 5 -alpha reductase inhibitor's attenuates erectile function by inhibiting autophagy and promoting apoptosis of smooth muscle cells in corpus cavernosum of aged rats.Urology 2013;82:743:.e9-15.

[14] Pinsky MR, Gur S, Tracey AJ, Harbin A, Hellstrom AJ.The effects of chronic 5-alpha reductase inhibitor(dutasteride )treatment on rat erectile function.J Sex Med 2011;8:3066-74.

[15] OztekinCV, Gur S, Abdulkar NA, Lokman U, Akdemir 0 , Cetinkaya $\mathrm{M}$, et al.Incomplete recovery of erectile function in rat after discontinuation of dual 5-alpha reductase inhibitor therapy . J Sex Med 2012;9:1773-81.

[16] Poletti A, Coscarella A, Negri-Cesi P, Colciago A, Celloti F, Martini . $-5-\alpha$ reductaseIsozymes in the central nervous system.Steroids 1998;63:246-51.

[17] Poletti A, Martini L. Androgen activating enzymes in the central nervous system..JSteroidBiochem Mol Biol 1999;69:117-22.

[18] Griffin JE, Wilson JD.The resistance syndromes5 - $\alpha$ reductase deficiency, testicular feminization and related disorders.In-Boudet AL, Sly WS, Valle D, editors. The metabolic basis of inherited disease.New York. Mckraw Hill;1989:1919-44.

[19] Griffin LD, Melon SH.Selective serotonin reuptake inhibitors directly alter activity of neurosteroidogenic enzymes.Proct Natl Acad Sci USA1999;96:13512-7.

[20] Kokate TG, Banks MK, Magee T, Yamaguchi S, Rogawski MA. Finasteride, A. 5- $\alpha$ reductase inhibitor, blocks the anticonvulsant activity of progesterone in mice.J Pharmacol Exp Ther 1999;288:679-84.

[21] Griffin LD, Gong W, Verot L, Melon SH.NiemannPick type $\mathrm{C}$ disease involves disrupted neurosteroidogenesis and responds to allopregnanolone .Nat Med 2004;10:704-11.
[22] Djeballi M, Guo Q, Pettus EH, Hoffman SW, Stein DG.The neurosteroids progesterone and allopregnanolone induce cell death, gliosis and functional deficits after traumatic injury in rats.J Neurotrauma 2005;22:106-18.

[23] Walf AA, Sumida K, Frye CA.Inhibiting 5- $\alpha$ reductase in the amygdale attenuates antianxiety and antidepressive behaviour of naturally receptive and hormone primed ovariectomized rats. Psychpharmacology(Berl) 2006;186:302-11.

[24] King SR.Emerging roles of neurosteroids in sexual behaviour and function.J Androl 2008;29:524-33.

[25] Reddy DS. Neurosteroids:endogenous role in the human brain and therapeutic potentials. Prog Brain Res 2010;186:113-37.

[26] Romer B, Pfeiffer N, Lewicka S, BenAbdallah N, VogtMA, Deutsche M, etal. Finasteride treatment inhibits adult hippocampal neurogenesis in male mice. Pharmacopsychiatry 2010;43:174-8.

[27] MoralliGI,MontesP,Gonzalez-BurgosI,Velasquez -Zamora DA, Cervantes M, Cytoarchitectural characteristics of hippocampal CA1pyramidal neurons of rats, four months after global central ischemia and progesteronetreatment.Restor Neurol Neurosci 2012;30:1-8.

[28] Caccioppo JT, Caccioppo S, Capitano JP, Cole SW.The neuroendocrinology of social isolation.. Annu Rev Psychol 2015;66:733-67.

[29] Melcangi RC, Panzica GC. Allopregnanolone: State of the art. Prog Neurobiol 2014;113:1-5.

[30] Melcangi RC.Caruso D, Abbiati F, Giatti S, Calabrese D, Piazza F, et al. Neuroactive steroid levels are modified in cerebrospinal fluid and plasma ofpost - Finasteride., patients showing persistent sexual side effects and anxious/ depressive symptomatology. J Sex Med 2013;10:2598-603.

[31] Caruso D, Abbiati F, Giatti S, Romano S, Fusco L, Calavetti G, et al. Patients treated for male pattern hair with Finasteride show, after discontinuation of the drug, altered levels of Neuroactive steroids in cerebrospinal fluid and plasma. JSteroidBiochem Mol Biol 2015;146:74-9. 
Post-Finasteride Syndrome - When will we Get the Courage to Fight the Dictating Pharma Industry - Despite Awareness of "Sexual, Neurological and Metabolic Side Effects in Young Men for Over a Decade"

[32] Melcangi RC, Santi D, SpezzanoR, Grimoldi M, Tabacchi T, Fusco ML , et al. Neuroactive steroids level and psychiatric and andrological features in post- Finasteride patients. JSteroidBiochem Mol Biol 2017;171:229-35.

[33] Gunduz-Bruce H, Silber C, Kaul I, Rothschild AJ, Riesenberg R, Sankoh AJ, et al.Trial of SAGE -217 in Patients with major depressive disorder. $\mathrm{N}$ Engl J Med 2019;381:903-11.

[34] Traish AM., The post - Finasteride syndrome: clinical manifestations of drug induced epigenetics due to endocrine disruption. Current Sexual Health Reports 2018;10:88-103.

[35] National Institute of Health:adverse eevents of 5- $\alpha$ reductase inhibitors.Available at :http:// rare diseases .info.nih.gov/diseases/12407/ post - finasteride -syndrome.Last accessed January 29, 2020.

[36] Ganzer CA, Jacobs AR.Emotional consequences of Finasteride:fool's gold.Am J Mens Health 2018;12:90-5.

[37] Ganzer CA, Jacobs AR, Iqbal F.Persistent sexual, emotional and cognitive impairment post finasteride:a survey of men reporting symptoms. Am J Mens Health 2015;9:222-8.

[38] Walf AA, Kaurejo S, Frye CA. Research brief:self reports of a constellation of Persistent antiandrogenic, estrogenic, physical and psychological effects of Finasteride usage among men. Am J Mens Health 2018;12:900-6.

[39] Basaria S, Jasuja R, Huang G, Wharton W, Pan $\mathrm{H}$, Pencina $\mathrm{K}$, et al. Characteristics of men who report Persistent sexual symptoms after Finasteride use for hair loss. J Clin Endocrinol Metab 2016;101:4669-80..

[40] Giatti S, Diviccaro S, Panzica G, Melcangi RC. Post - Finasteride syndrome and post -SSRI sexual dysfunction:two sides of the same coin? Endocrine 2018;61:180-93.

[41] Healy D, Le Noury J, Miteva M.Enduring sexual dysfunction after treatment with antidepressants, 5- $\alpha$ reductase inhibitors and isotretinoin:300 Cases .Int J Risk Saf Med 2018;29:125-34.
[42] Mervis JS, Borda LJ, Miteva M. Post - Finasteride syndrome:What to tell our female patients.Br J Dermatol 2018;179:785-6.

[43] Maksym RB, Kajdy A, Rabijewsky M. .Post Finasteride syndrome:Does it really exist?Aging Male 2019;16:1-10.

[44] Gray SL, Semla TP. Post - Finasteride syndrome. BMJ 2019;366:15047.

[45] Rezende HD, Dias MFRG, Trueb RM.Acomment on Post - Finasteride syndrome. Int J Trichology 2018;29:125-34.

[46] Trueb RM.Reginer A, Dutra Rezende H, Gavazzoni Dias MFR. Post - Finasteride syndrome-:An induced delusional disorder with the potential of a mass psychogenic illness?Skin Appendage Disord 2019;16:1-10.

[47] Traish AM. Post - Finasteride syndrome-:A surmountable challenge for clinicians .Fertil Steril 2020;113(1):21-50.

[48] Irwig MS, Kolukulka S. Persistent sexual side effects of finasteride for male pattern hair loss. J Sex Med 2011;8:1747-53.

[49] Irwig MS. Persistent sexual side effects of finasteride:could they become permanent? J Sex Med 2012;9:2927-32.

[50] Irwig MS. Depressive symptoms and suicidal thoughts among former user of finasteride with Persistent sexual side effects.J Clin Psychiatr 2012;73:1220-3.

[51] Irwig MS.Androgen levels and semen parameters former user of finasteride with Persistent sexual side effects.J Am Med Assoc Dermatol 2014;150:1361-3.

[52] Irwig MS.Safety concerns regarding 5- $\alpha$ reductase inhibitors for the treatment of Androgenic alopecia.Curr Opin Endocrinol Diabetes Obes 2015;22:248-53.

[53] Rahimi-Ardabili B, Pourandarjani R, Habi bollahi P, Mualeki A. Finasteride induced Depression:a prospective study .BMC Clin Pharmacol 2006;6:7.

[54] Romer B, Gass B. Finasteride induced Depression:New insights into possible 
Post-Finasteride Syndrome - When will we Get the Courage to Fight the Dictating Pharma Industry - Despite Awareness of "Sexual, Neurological and Metabolic Side Effects in Young Men for Over a Decade"

pathomechanisms. J Cosmet Dermatol 2010;9: $331-2$.

[55] Chiba K, Yamaguchi K, Li F, Ando M, Fujisawa M. Finasteride-associated male fertility .Fertil Steril 2011;95:1786e9-11.

[56] Liu KE, Binsaleh S, Lo KC, Jarvi K, Proapeciainduced spermatogenic failure:a report of 2 cases. Fertil Steril 2008;90:849.e17-9.

[57] Tu HY, Zini A. Finasteride induced secondary fertility Associated with sperm damage . Fertil Steril2011;95:2125e13-4.

[58] WongAC,MaskST.Finasterideassociated cataract and intraoperative floppy -iris syndrome.J CataractRefract Surg 2011;37:1351-4.

[59] Santo Domingo D, Stevenson ML, Auerbach J, Lerman J. Finasteride induced Pseudoporphria. Arch Dermatol 2011;37:1351-4.

[60] Tresch S, Cozzio A.Kamarshev J, Harr T, Schmid Grandelmeier P, French LE, et al.T-cell mediated acute localized exanthematous pustulosis caused by Finasteride.J Allerrgy Clin Immunol 2012;129:589-94.

[61] BelknapSM, Aslam I, Kiguradze T, Temps WH, Yarnold PR, Cashy J, et al.Adverse events reporting in clinical trials of Finasteride on androgenic alopecia:a meta-analysis.JAMA Dermatol 2015;151:600-6.

[62] Kiguradze T, Temps WH, Yarnold PR, Cashy J, Brannigan RE, Nardone $P$, et al. Persistent erectile dysfunctionin men exposed to 5- $\alpha$ reductase inhibitors, finasteride or dutasteride . Peer J 2017;5:e3020.

[63] Fertig RM, Gamret AC, Darwin E, Gaudi S. Sexual side effects of 5- $\alpha$ reductase inhibitors, finasteride or dutasteride: A Comprehensive review. Dermatol Online 2017;23.

[64] Fertig RM, Shapiro J, Berkfeld W. Tosti A. Investigation of the Plausibility of 5- $\alpha$ reductase inhibitor syndrome.Skin Appendage Disord 2017;2:120-9.

[65] Thompson IM, Goodman PJ, Tangen CM, Lucia MS, Miller GJ, Ford LG, et al.The influence of finasteride on the development of prostate cancer. N Engl J Med 2003;349:215-24.
[66] Wessels H, Roy J, Bannow J, Grayhack J, Matsumoto AM, Tenover $\mathrm{L}$, et al. Incidence and severity of Sexual Adverse experiences in finasteride and placebo treated men with benign prostatic hyperplasia.Urology 2003;61:579-84.

[67] Kaufman KD, Olsen EA, Whiting D, Savin R, De Villez R, Bergfeld W, et al. Finasteride in the treatment of men with androgenic alopecia. Finasteride male pattern hair loss Study Group.J Am Acad Dermatol 1998;39(4Pt 1):578-89.

[68] Roehrborn CG, Boyle P, Nickel JC, Hoefner K, Andriole G.Efficacy and safety of a dual inhibitor of 5- $\alpha$ reductase type 1 and 2(dutasteride) in men with benign prostatic hyperplasia. Urology 2002;60:434-41.

[69] Roehrborn CG, Siami P, Barkin J, Damiio-R, Major Walker K, Morrill B, et al.The effect of dutasteride, tamulosin and combination therapy on lower urinary tract symptoms in men with benign prostatic hyperplasia and prostatic enlargement :2year results from the CombAT Study.J Urol 2008;179:616-21.

[70] Roehrborn CG, Perez JO, Roos EP, Calomfirescu N, Brotherton B, Wang F, Palacios JM, Vasyley A, Manyak MJ. Efficacy and safety of a fixed dose combination of dutasteride and tamulosin treatment(DuodartTM)compared with watchful waiting with initiation of tamulosin therapy if symptoms do not improve, both -provided with lifestyle advice, in the management of treatment naive men with moderately symptomatic benign prostatic hyperplasia:2 year CONDUCT study results.BJU Int 2015;116:450-9.

[71] Nickel JC, Fradet Y, Boake RC, Pommerville PJ, Perreault JP, Afridi SK, et al. Efficacy and safety of Finasteride therapy for benign prostatic hyperplasia:results of a 2 year randomised controlled trial(the PROSPECT study).PROscar Safety Plus Efficacy Canadian Two -year study. CMAJ 1996;155:1251-9.

[72] Marbenger MJ.Long term effects of Finasteride in patients with benign prostatic hyperplasia:a double blind, controlled trial, multicenter study. Urology 1998;51:677-86.

[73] Hudson PB, Boake R, Trachtenberg J, Romas NA, Rosenblat S, Narayan P, et al. Efficacy of 
Post-Finasteride Syndrome - When will we Get the Courage to Fight the Dictating Pharma Industry - Despite Awareness of "Sexual, Neurological and Metabolic Side Effects in Young Men for Over a Decade"

Finasteride is maintained in patients with benign prostatic hyperplasia treated for 5 years. The North American Finasteride study. Urology 1999;53:690-5.

[74] Edwards JE, Moore RA. Finasteride in the treatment of clinical benign prostatic hyperplasia:asystematic review of randomised trials.BMC Urol2002:2:14.

[75] AUA Practice Guidelines Committee. AUA Guidelines on management of benign prostatic hyperplasia.Chapter 1: diagnosis and treatment recommendations. J Urol 2003;170:530-47.

[76] Debruyne F, Barkin J, Van Erps P, Reis M, Tammela TL, Roehrborn CG, et al. Efficacy and safety of longterm treatment with the dual $5-\alpha$ reductase inhibitor dutasteride in men with symptomatic benign prostatic hyperplasia.Eur Urol 2004;46:488-94.

[77] Siami P, Roehrborn CG, Barkin J, Damiio-R, Wyczolkowski M, Duggan A, et al. Combination therapy with dutasteride and tamulosin in men with moderate to severe benign prostatic hyperplasia prostatic enlargement : the CombAT(Combination of Avodart and tamulosin )trial rationale and Study design.Control Clin Trials 2007;28:770-9.

[78] Amory JK, Wang C, Swerdloff RS, Anawalt BD, Matsumoto AM, Brenner WJ, et al.The , et al.5- $\alpha$ reductase inhibition with dutasteride and Finasteride on semen parameters and serum hormones in healthy men. J Clin Endocrinol Metab 2007;92: 1659-65.

[79] Amory JK, Anawalt BD, Matsumoto AM, Page ST.The effect of $5-\alpha$ reductase inhibition with dutasteride and Finasteride on bone mineral density, serum lipoproteins, haemoglobin, prostate specific antigen, and sexual functions in healthy young men. J Urol 2008;179:2333-8.

[80] Kaplan SA, Chung DE, Lee RK, Scofield S, Te AE.A 5 year retrospective analysis of $5-\alpha$ reductase inhibitors in men with benign prostatic hyperplasia: Finasteride has comparable urinary symptoms efficacy and prostate volume reduction, but less sexual side effects and breast complications than dutasteride. Int J Clin Pract 2012;66:1052-5.
[81] Fwu CW, Eggers PW, Kirkali Z, McVary KT, Burrows PK, Kusek JW. Change in sexual function in men with lower urinary tract symptoms(LUTS)/ benign prostatic hyperplasia(BPH)associated with longterm treatment with doxasozin, Finasteride and combined therapy. J Urol 2014;191:1828-34.

[82] Andriole GL, Bostwick DG, Brawley OW, Gomella LG, Marbenger M, Montorsi F, et al. Effect of dutasteride on the risk of prostate cancer. N Engl J Med 2010;362:1192-202.

[83] Andriole GL, Kirby R.Safety and tolerability of the dual 5- $\alpha$ reductase inhibitor dutasteride in the treatment of benign prostatic hyperplasia. Eur Urol 2003;44:82-8.

[84] Moinpour CM, Darke AK, Donaldson GW, Thompson IM Jr, Langley C, Ankerst DP, et al. Longitudinal analysis of sexual function reported by men in the prostate cancer prevention trial.J Natl Cancer Inst 2007;99:1025-35

[85] Brenner S, Matz H.Improvement in androgenic alopecia in 5376 -year old men using oral Finasteride.Int J Dermatol 1999;38:928-30.

[86] Gormley GJ, Stoner E, Brukewicz RC, ImperatoMcGinley J, McConell J, Walsh PC, McConell JD, et al.The : Finasteride study Group. N Engl J Med1992;327:1185-91.

[87] Vaughan D, Imperato-McGinley J, McConell J, Matsumoto AM, Bracken B, Roy J, et al.Longterm (7-8 year)experience with Finasteride in men with benign prostatic hyperplasia. Urology2002;60:1040-4.

[88] Ali AK, Heran BS, Etminan M. Persistent sexual dysfunction and suicidal ideation in young men treated with low-dose finasteride:a pharmacovigilance study. Pharmacotherapy 2015;35:687-95.

[89] Chiriaco G, Cauci S, Mazzon G, Trombetta C.An observational retrospective evaluation of 79 young men with Longterm adverseeffects after use of finasteride against androgenic alopecia. Andrology 2016;4:245-50.

[90] GuoM, Heran BS, Flannigan R, Kezou A, Etminan M. Persistent sexual dysfunction with finasteride $1 \mathrm{mg}$ taken for hair loss. Pharmacotherapy 2016;36:1180-4. 
Post-Finasteride Syndrome - When will we Get the Courage to Fight the Dictating Pharma Industry - Despite Awareness of "Sexual, Neurological and Metabolic Side Effects in Young Men for Over a Decade"

[91] Choi GS, Kim JH, Oh SY, Park JM, Hong JS, Lee YS, Lee WS.Safety and tolerability of the dual $5-\alpha$ reductase inhibitor dutasteride in the treatment of androgenic alopecia.Ann Dermatol 2016;28:444-50.

[92] Di Loreto C, La Marra F, Mazzon G, , Belgrano E, TrombettC, Cauci S.Immunohistochemical evaluation of androgen receptor and nerve structure density in human prepuce from patients with Persistent sexual side effects after finasteride use for androgenic alopecia.PLoSOne 2014;9:e100237.

[93] Gubelin Harcha W, Baboza-Martinez J, Tsai TF, Katsuoka K, Kawashima M, Tsuboi R, et al.A randomised, active and placebo controlled study of the Efficacy and safety ofdifferent doses of dutasteride versus placebo and finasteride in the treatment of male subjects with androgenic alopecia.J Am Acad Dermatol 2014;70:489-98.

[94] Olsen EA, Whiting DA, Savin R, Rodgers A, Johnson-LevonasAD, Round E, et al.Male pattern hair loss study Group.global photographic assessment of men aged 18 to60years with Male pattern hair loss receiving finasteride img or placebo. J Am Acad Dermatol 2012;67:379-86.

[95] Sato A, Takeda A.Evaluation of Efficacy and safetyof finasteride $1 \mathrm{mg}$ in 3177 Japanese men with androgenic alopecia. J Dermatol 2012;39:27-32.

[96] Kaufmann KD, Rotonda J, Shah AK, Meehan AG. Longterm treatment of finasteride $1 \mathrm{mg}$ decreases the likelihood of developing further visible hair loss in men with androgenic alopecia(Male pattern hair loss)Eur J Dermatol 2008;158:400-6.

[97] Olsen EA, Hordinsky M, Whiting DA, Stough D, Hobbs S, Ellis ML, et al. Dutasteride Alopecia Research Team. The importance of dual $5-\alpha$ reductase inhibition in the treatment of Male pattern hair:results of a randomised, placebo controlled study of dutasteride versus finasteride. J Am Acad Dermatol 2006;55:1014-23.

[98] Price VH, Menefee A, Sanchez M, Kaufman KD. Changes in hair weight in men with androgenic alopecia after treatment with finasteride $(1 \mathrm{mg}$ daily): three and 4 year results . J Am Acad Dermatol 2006;55:71-4.

[99] Leavitt M, Perez-Meza D, Rao NA, Barusco M, Kaufman KD, Ziering C.Effects of finasteride (1mg)on hair transplant.Dermatol Surg 2005;31:1268-76.

[100] Atomare G, Capella GL. Depression, Circumstantiability related to the administration of finasteride for androgenic alopecia. J Dermatol 2002;29:665-9.

[101] Kaufman KD. Finasteride Male pattern hair loss study Group. Longterm (5 year) multinational experience with finasteride $1 \mathrm{mg}$ in the treatment of men with androgenic alopecia. Eur J Dermatol 2002;12:38-49.

[102] Price VH, Menefee E, Sanchez M, Ruane P, Kaufman KD.Changes in hair weight and hair count in men with androgenic alopecia after treatment with finasteride $1 \mathrm{mg}$ daily. J Am Acad Dermatol 2002;46:517-23.

[103] Roberts JL, Fiedler V, Imperato-McGinley J, Whiting DA, Olsen EA, Shupack J, et al.Clinical dose ranging studies with finasteride, a type 2 , 5 - $\alpha$ reductase inhibitor, in men with Male pattern hair loss. J Am Acad Dermatol 1999;41:555-63.

[104] Dallob AL, Sadick NS, Unger W, Upert S, Geissler LA, GregoireSL,etal.TheEffectoffinasteride, a $5-\alpha$ reductase inhibitor, on scalp skin testosterone and dihydrotestosterone concentrations in patients with Male pattern baldness . J Clin Endocrinol Metab 1994;79:703-6.

[105] Mella JM, Perret MC, Manzotti M, Catalano HN, Guyatt G. Efficacy and safetyof finasteridetherapy for androgenic alopecia: a systematic review. Arch Dermatol 2010;146:1141-50.

[106] Zakhem GA, Goldberg JE, Motosko CC, Cohen BE, Ho RS.Sexual dysfunction in men taking dermatologic medication :a systematic review. J Am Acad Dermatol 2019;81:163-72.

[107] Lee S, LeeYB, Choe SJ, Lee WS. Adverse sexual effects of treatment with finasteride or dutasteride for male androgenic alopecia: a systematic review and meta-analysis.Acta Derm Venereol 2019;99:12-7. 
Post-Finasteride Syndrome - When will we Get the Courage to Fight the Dictating Pharma Industry - Despite Awareness of "Sexual, Neurological and Metabolic Side Effects in Young Men for Over a Decade"

[108] Lee SW, JuhaszM, Mobasher P, Ekelem C, Mesinovska NA.A systematic review of topical finasteride in the treatment of androgenic alopecia in men and women.J Drugs Dermatol 2018;17:457-63.

[109] Adil A, Godwin M.The effectiveness of treatments of androgenic alopecia: a systematic review and meta-analysis. J Am Acad Dermatol 2017;77:136-41.e5.

[110] Corona G, Tirabassi G, Santi D, Maseroli E, Gacci M, Dicuio M, et al. Sexual dysfunction in subjects treated with inhibitors of 5- $\alpha$ reductase for benign prostatic hyperplasia. Andrology 2017;5:671-8.

[111] Hirschburg JM, Kelsey PA.Therrien CA, Gavino AC, Reichenberg JS. Adverse effects and safety of $5-\alpha$ reductase inhibitors(finasteride, dutasteride) :a systematic review.J Clin Aesthet Dermatol 2016;9:56-62.

[112] Liu L, Zhao S, Li F, Kang R, Luo L, Wan S, Zhao Z. Effect of 5- $\alpha$ reductase inhibitors on Sexual function: a meta-analysis and systematic reviewof randomised controlled trials. J Sex Med 2016;13:1297-310.

[113] Hagbery KW, Divan HA, Persson R, Nickel JC, Jick SS.Risk of erectile dysfunction associated use of 5 - $\alpha$ reductase inhibitors in benign prostatic hyperplasia or alopecia:population based studies using the Clinical Practice Research Datalink .BMJ 2016;354:14823.

[114] Park T , Choi JY. Efficacy and safety of dutasteride for the treatment of symptomatic benign prostatic hyperplasia(BPH) : a systematic review and meta-analysis.World J Urol 2014;32:1093105.

[115] Corona G, Rastrelli G, Maseroli E, Balercia G, Sforza A, Forti $G$, etal. Inhibitors of 5 - $\alpha$ reductaserelated side effects in patients seeking medical care for Sexual dysfunction.J Endocrinol Invest 2012;35:915-20.

[116] Gray GD, Smith ER, Davidson JM, Hormonal regulation of penile erection in castrated male rats.Physiol Behav1980;24:463-8.

[117] Saksena SK, Lau IF, Chang MC.The inhibition of the conversion of testosterone to $5-\alpha-$ dihydrotestosterone in the reproductive organs of the male rats.Steroids 1976;27:751-7.

[118] Baum MJ. A comparison of the effects of methyltrienolone (R1881) and 5- $\alpha$ dihydrotestosterone on Sexual behaviour of castrated male rats. Horm Behav1979;13:165-74.

[119] Schule C, Nothdurfter C, Rupprecht R. The role of allopregnenolone in depression and anxiety. Prog Neurobiol 2014;113:79-87.

[120] Butcher M, BassW, Lwin A, Holland B, Herberts M, Cemons J, et al. Post Finasteride Syndrome:Real or Imagined?J Urology 2016;195:e1139.

[121] Narsimhalu CR. Randomised questionnaire based case-control research study on evaluation of Sexual function in Indian patients taking oral finasteride for androgenic alopecia. Dermatol Ther(Heidelb)2015;5:231-4.

[122] Shanshanwal SJ, Dhurat RS.Superiority of dutasteride over finasteride in hair regrowth and reversal of miniaturization of men with androgenic alopecia:A Randomised controlled, open label, evaluator blinded study. Indian J Dermatol Venereol Leprol 2017;83:47-54.

[123] Kaufman KD.Androgen metabolism as it affects hair growth in androgenic alopecia:. Dermatologic Clinics 1996;14:697-711.

[124] Tsunemi Y, Irisawa R, Yoshiie H, Brotherton B, Ito H, Tsuboi R, et al. AR114264 Study Group. Longterm safety and efficacy of of dutasteride in the treatment of male patients with androgenic alopecia.J Dermatol 2016;43:1051-8.

[125] Moore TJ. Finasteride and the uncertainties of establishing harms. JAMA Dermatol 2015; 151:586.

[126] Roehrborn CG, Brukewicz RC, Nickel JC, McConell JD, Saltzman B.Gittelman MC, et al.Proscar Longterm Efficacy and safety study Group. Sustained decrease in incidence of acute urinary retention and surgery with finasteride for 6 years in men with benign prostatic hyperplasia.J Urol 2004;17:1194-8.

[127] Kirby RS, Roehrborn CG, Boyle P, Bartsch G, Jardin A, Cary MM.Sweeney M, Grosman EB.Prospective European Doxazosin and Combination Therapy 
Post-Finasteride Syndrome - When will we Get the Courage to Fight the Dictating Pharma Industry - Despite Awareness of "Sexual, Neurological and Metabolic Side Effects in Young Men for Over a Decade"

study Investigators. Efficacy and tolerability of Doxazosin and finasteride, alone or in Combination, in treatment of symptomatic benign prostatic hyperplasia.:The Prospective European Doxazosin and Combination Therapy(PREDICT) trial. Urology2003;61:119-26.

[128] Roehrborn CG, LeeM, Meehan A, Waldstreitcher J.PLESS study Group. Effects of finasteride on serum testosterone and body mass index in men with benign prostatic hyperplasia. Urology2003;61:894-9.

[129] Gupta AK, Charrette A.The Efficacy and safety $5-\alpha$ reductase inhibitors:a network meta-analysis and benefit risk assessment of finasteride and dutasteride .J Dermatol Treat 2014;25:156-61.

[130] Gupta AK, Sharma N, Shukla P.Atypical Post Finasteride Syndrome:a pharmacological riddle. Indian J Pharmacol2016;48:316-7.

[131] Alberts VA, Catalano G, Poole MA.Tardive dyskinesia as a result of longterm prochlorperazine use. South Med J 1996;89:989-91.

[132] Ananthi J.Drug induced dyskinesia :a critical review.Int Pharmacopsychiatry1079;14:21-33.

[133] Browning DH, Ferry PC. Tardive dyskinesia in a ten year old boy. An undesirable sequel of phlorthiazine medication. Clin Paedtr(Phil) 1976;15:955-7.

[134] Ahmad K, Dorian P. Drug induced QT prolongation and proarrythmia :am inevitable link ? Europace 2007;9(Suppl 4):iv16-22.

[135] Roden DM. Drug induced long QT syndrome. Pharmacol Rev 2010;62:760-81.
[136] Koningstein M, Rozzo R, Topaz G, Postema PG, Friedenson L, Heller K, et al. Drug induced Brugada Syndrome.Clinical characteristics and risk factors. Heart Rhythm 2016;13:1083-7.

[137] Mintzer DM, Billet SN, Chmielewski l.Drug induced haematologic syndromes. Adv Haematol 2009;2009:495863.

[138] Izzedine H, Launay-Vacher v, Isnard Bagnis C, Deray G. Drug induced Fanconi syndrome.Am J Kidney Dis 2003;41:292-309.

[139] Golder S, Loke YK, Wright K, Norman G.Reporting of Adverseevents in published and unpublished studies of health care interventions: a systematic review PLoS Med 2016;13:e1002127.

[140] Kaptchuk TJ.The double blind, randomised, placebo controlled trial, :gold standard or golden calf?J Clin Epidemiol 2001;54:541-9.

[141] Wei L, Lai EC, Kao-Yang YH, Walker BR, MacDonald DM, Andrew R.Incidence of type 2 diabetes mellitus in men receiving Steroid 5-alpha reductase inhibitors:population based cohort study.BMJ 2019;365:11204.

[142] Baig MS , Kolasa-Wolosiuk A, Safranow K, Barnowski -Bosiacka I, Kabat Koperska J, Wisniewska B. Finasteride induced inhibition of 5-alpha reductase type 2 could lead to kidney damage -animal, experimental study .Int J Environ Res Public Health 2019;16:1726.

[143] Traish AM. Health Risks of Long-Term Use of Finasteride and Dutasteride:its time to sound the alarm.World J Men's Health 2020; 1-15. https://doi.org/10.5534/wjmh.200012

Citation: Dr. Kulvinder Kochar Kaur, Dr. Gautam Allahbadia, Dr. Mandeep Singh. Post-Finasteride Syndrome - When will we Get the Courage to Fight the Dictating Pharma Industry - Despite Awareness of "Sexual, Neurological and Metabolic Side Effects in Young Men for Over a Decade". Archives of Urology. 2020; 3(1): 10-30.

Copyright: (c) 2020 Dr. Kulvinder Kochar Kaur, Dr. Gautam Allahbadia, Dr. Mandeep Singh. This is an open access article distributed under the Creative Commons Attribution License, which permits unrestricted use, distribution, and reproduction in any medium, provided the original work is properly cited. 